\title{
ESSENTIAL ELEMENTS IN LAND CLASSIFICATION ${ }^{1}$
}

\author{
L. R. Schoenmann
}

School of Forestry and Conservation University of Michigan

\begin{abstract}
Michigan's first Director of Conservation concluded a six-year term of service with the observation that "Conservation was like a wheelbarrow. It moved only when pushed." He wisely left the relation of the pushee and conservation's devious course to inference. Land classification, it appears, has developed under the influence of similar stimulants and controls.

The record of "bar" killings that
\end{abstract}

Dan'l Boone left on the beech trees of the Ohio River watershed has endured, but the verbally reported land classification that he took back to the land hungry settlers of the seaboard colonies has been lost.

Indian fighting was not the lure that sent the pioneer scouting expeditions through the gaps of the Appalachian ranges. They fanned out through the western wilderness to classify land for the migrant tide of settlement that was to follow.

The Government Land Survey and the Hayden, Powell and Wheeler exploratory surveys were among the early and more systematic officlal attempts at land classification.

Somewhat later on, technique in land classification was still further advanced by the work of the U. S. Geological Survey in several western states, and the classification that was carried on in the newly created National Forest Reserves.

The soil survey that was inltiated with the turn of the century gave us a serviceable system for identifying, charting, and correlating the soil character of land areas. That in itself was an outstanding achievement, but 1ts principal value for land classification arose from the fact that the soil mapping provided a reference frame to which the findings of the agricultural experiment stations and the experience of practical farmers could be related, and consequently used, in determining the suitability of land areas for agricultural production. The improvements that the recent years have brought into soil classification and mapping has simply served to enhance the serviceability of this tool for land classification. Under the stresses that followed the World War, our soclal-economlc fabric was so strained in its weak spots that the land problems which had been incubating here and there for some time began to show quite plainly, and the manner in which several states went about determining the extent of the damage, its nature, cause, and amelioration led to notable improvements in methods of land inventory and classification.

The recent depression has given great impetus to land classification. Quite generally, the pre-depression conditions that had been urging land classification still exist. In addition, a number of new agencies have been charged with respons1bility for attention to one phase or another of our growing land use problems and respectively implemented with an action program which it is their duty to seat as intelligently as possible into place. A more fertile seed bed for new developments in land classification could hardly be lmagined and, as might be expected, schemes, systems, and programs for "land classification" have sprouted so fast that I doubt whether any one of us has even a casual acquaintance with more than a fraction of the work now underway. Certalnly, much good must come out of all this activity about land classification.

In view of the broad scope of the work that is now going on under the name of

${ }^{1}$ Read before Joint Session of the American Soll Survey Association and the Soils Section, American Society of Agronomy at Weshington, D. C., November 18, 1936. 
land classification and the variety of interests that this work is attempting to serve, I wish to suggest that the foremost essential. in a possible list of Essential Elements in Land Classification should be a clear and complete definition of why the proposed classification is needed and how it will be used when completed. Thought on this score will tend to sharpen the efficiency and effectiveness of the undertaking and help to make it something more than just another scheme in land classification.

Land cannot be readily moved about for the sake of convenience and economy in use. It must be used in situ. The location and area of differing kinds and grades of land therefore become matters of important practical consequence in land classification. These attributes of land and their coincident environmental influences can be most appropriately and serviceably displayed on maps. Suitable cartographic expression of the required preliminary data and the subsequent conclusions is therefore indicated as a further essential element in land classification. Aerial photography has opened a wide door of possibility to this essential but it has not made an automatic settlement of the choice of scale, degree of detail, and accuracy for added values, legibility, etc. Items of such character still require discriminating consideration in the light of the objectives to be served by the classification.

The inherent characteristics of land, such as type of soil, degree of slope, stoniness, and the climatic environment are so fundamental to land classification that such items are not in serious danger of being disregarded in authentic attempts at land classification. Their relationship to land usage has become progressively more certain as our knowledge has been sharpened and focused by experience, experiments, and study. The weight of such items forces their recoznition. There is some danger, however, that certain other influential factors may be underrated or disregarded. Among such, we might list the indicated trend in the probable demand for given uses or their products, the present owring agency and its purpose or intent in ownership, the established uses and their occupance patterns, the stage to which transitory uses may have progressed, retarding or facilitating customs, regulations or laws, etc. While influences of this nature are open to change, the moment and degree of possible change is seldom predictable except on the basis of past trends. But the certainty that these factors will. be operating and exerting some shade of influence must be reckoned with, and prompts their inclusion in this list of essential elements in land classification.

The admission of these factors as elements in land classification develops a need for recognizing a unit of land character that is broader than the soil type, more restricted than the soil group, and capable of areal delineation. This unit of land character should summarize the dominant nature of the soil - slope - erosion - drainage - adaptation complex in such a manner as to provide a reliable reference frame against which the factors enumerated above can be projected on a scale that harmonizes with the manner of their occurrence. Thus, serviceable correlations may be established between land character and the other essential factors that affect land use. Valid generalizations in land character of this order can be made from the soil maps wherever a classification of slope and erosion was carried on concurrently with the soil mapping, or can be added.

Land use and its attendant problems show a recognized regionalization. This prompts the suggestion that orientation of studies and undertakings in land classification on a similar basis offers more promise for the development of serviceable methods and results than either a simple national approach or an accidental local effort. The extent to which various Federal agencies with responsibilities in land affairs have regionalized their operations and personnel supports this thought. While this proposal may not rate as an essential element. in land classification, it might well become an important means for accomplishing improvement in technique. This would be especially true if it served to draw local workers into close coöperative contact with other workers in the same field throughout the region, and if it invited participation on the part of those disciples possessing competence for dealing with the whole physical, economic, social, and political complex. 